\title{
Long-term Treatment of Chronic Myeloid Leukemia
}

\author{
Akif Selim YAVUZ \\ Istanbul University Istanbul Faculty of Medicine, Department of Internal Medicine, \\ Division of Hematology, Istanbul, TURKEY
}

\begin{abstract}
Imatinib, a selective tyrosine kinases inhibitor (TKI), has excellent efficacy in the treatment of chronic myeloid leukemia (CML). Imatinib resistance and intolerance opened the way to the development of second generation TKIs against CML, including nilotinib and dasatinib. Because all TKIs are more effective drugs in comparison with previous therapies in CML, the followup period is now longer in the TKI era. These compounds are prescribed for prolonged periods, often in patients with comorbidities. Therefore, monitoring of CML should comprise the response to TKIs and long term effects of the TKIs.
\end{abstract}

Keywords: Chronic myeloid leukemia, Long term treatment, Monitorization

\section{ÖZET}

\section{Kronik Myeloid Löseminin Uzun Dönem Tedavisi}

Selektif bir tirozin kinaz inhibitörü olan imatinib kronik miyeloid lösemi tedavisinde etkisini kanıtlamıştır. İmatinibe karşı gelişen direnç ve intolerans kronik miyeloid lösemide nilotinib ve dasatinib gibi ikinci jenerasyon tirozin kinaz inhibitörlerinin geliştirilmesine yol açmıştır. Tirozin kinaz inhibitörlerinin hepsi kronik miyeloid lösemide kullanılan ilaçlardan daha üstün oldukları için, hastaların takip süreleri de uzamıştır. Bu ilaçlar komorbiditesi de olan hastalarda uzun süreli olarak kullanılmaktadır. Bu yüzden kronik miyeloid lösemili hastaların monitorizasyonu hem tirozin kinaz inhibitörlerine yanıtı hem de bu ilaçların uzun dönemdeki etkilerini içermelidir.

Anahtar Kelimeler: Kronik miyeloid lösemi, Uzun süreli tedavi, Monitorizasyon 


\section{INTRODUCTION}

Chronic myeloid leukemia (CML) is a progressive and often fatal myeloproliferative neoplasm genetically characterized by the presence of the reciprocal translocation $\mathrm{t}(9 ; 22)(\mathrm{q} 34 ; \mathrm{q} 11)$ resulting in a bcr-abl fusion gene on the derivative chromosome 22, which is called Philadelphia $(\mathrm{Ph})$ chromosome. The resulting gene product is $\mathrm{BCR}-\mathrm{ABL}$ and the deregulated tyrosine kinase activity of this oncoprotein is responsible for leukemogenesis..$^{1-3}$ The natural history of CML consists of 3 distinct stages: chronic phase $(\mathrm{CP})$, accelerated phase (AP), and a blast phase (BP). ${ }^{4}$ Most patients (90\%) present with CML in CP.

In CP patients well differentiated leukemic cells are proliferating relatively slowly. CP is followed by $\mathrm{AP}$ and white blood cell counts are poorly controlled and the numbers of immature blasts in the peripheral blood are increased. ${ }^{5}$ After 1 to 2 years, AP may transit into BP. In this phase cytopenias, infections, bleeding, organ failure, and death can occur. The transition occurs as rapidly as 3 years in the absence of treatment. The median survival for patients with untreated BP CML is 3 to 6 months. ${ }^{5}$

With the advent of tyrosine kinase inhibitors (TKIs) to treatment of CML, the natural history of this disease changed dramatically in the last ten years and extremely longer survivals and longer follow-ups are expected for the CML patients. Thus, the number of CML patients is accumulating and the patients have to be closely monitored, as their TKI therapy continues.

\section{MONITORING RESPONSE IN CML}

The goals of CML treatment are to achieve normal blood count values, reduction and elimination of the $\mathrm{Ph}$ chromosome, and reduction and elimination of BCR-ABL transcripts. These goals can be monitored with the assessment of hematologic, cytogenetic, and molecular responses, respectively. Prior to the TKI therapy, the response to treatment was assessed with hematologic and cytogenetic measurements. Nowadays, the TKIs commonly achieve deep molecular responses and more sensitive techniques of disease detection are required.

\section{i. Hematologic Response}

A complete hematologic response (CHR) is achieved, when white blood cell count is $<10.000 / \mathrm{mm}^{3}$, platelet count is $<450.000 / \mathrm{mm}^{3}$, myelocytes plus metamyelocytes are $<5 \%$, blasts and promyelocytes in peripheral blood are absent, and extramedullary involvement is absent. ${ }^{6,7}$ European LeukemiaNet (ELN) recommends performing $\mathrm{CBCs}$ at diagnosis, then every 15 days until complete hematologic response (CHR) has been achieved and confirmed, then at least every 3 months or as required. According to ELN achievement of CHR within 3 months from the start of therapy is an optimal response and approximately all patients with CML in chronic phase achieve a CHR with TKI therapy.

\section{ii. Cytogenetic Response}

Cytogenetic analysis is the gold standard for response monitoring in CML. ${ }^{8}$ In conventional cytogenetics $>20$ metaphases from the bone marrow is required and the presence of the $\mathrm{Ph}$ chromosome is evaluated. Categories of cytogenetic response are the followings: minimal cytogenetic response (66\% to $95 \% \mathrm{Ph}^{+}$metaphases), minor cytogenetic response (\%36-65 $\mathrm{Ph}+$ metaphases), partial cytogenetic response, (1\% to $35 \% \mathrm{Ph}+$ metaphases), major cytogenetic response ( $0 \%$ to $35 \% \mathrm{Ph}^{+}$metaphases), and complete cytogenetic response $\left(0 \% \mathrm{Ph}^{+}\right.$metaphases). The association between cytogenetic response and positive outcomes has been established well. ${ }^{9}$

Fluorescent in situ hybridization (FISH) is an alternative technique for evaluating cytogenetic response. Approximately 200 interphase cells are analyzed from peripheral blood samples instead of bone marrow samples. Due to technical restrictions clinicians should be aware of the possibility of low-level false-FISH positivity in making a decision for treatment failure. Current data are based on conventional cytogenetics so FISH is only recommended prior to treatment to identify cases of $\mathrm{Ph}^{-}$, BCR-ABL+ CML, and those with variant Ph translocations, $\mathrm{Ph}$ amplification, or del9q+. ${ }^{1.7}$

According to the ELN recommendations conventional cytogenetics should be done at diagnosis, at 3 months, and at 6 months; then every 6 months until a CCyR (complete cytogenetic response) has been 
achieved and confirmed, then every 12 months if regular molecular monitoring can not be assured; always for occurrences of treatment failure and for occurrences of unexplained cytopenias. The achievement of CCyR at 12 months is considered as an optimal response to imatinib treatment. ${ }^{7}$

\section{iii. Molecular Responses}

The majority of patients with CML treated with TKI therapy achieve a complete cytogenetic response. Molecular monitoring is applied for detecting deeper responses. In this method the presence of BCR-ABL mRNA using real-time quantitative polymerase chain reaction (QPCR) is evaluated. ${ }^{10}$ This analysis can be performed on peripheral blood samples and is more convenient than bone marrow aspiration for the patient and clinician. ${ }^{11,12}$ The amount of reduction in BCR-ABL transcripts compared to a standardized baseline is assessed.? Individual laboratories can report BCR-ABL transcript levels on an international scale with the introduction of a conversion factor, which is specific for the individual laboratory. Thus, a comparison between the values of different laboratories is possible.

A major molecular response is defined as a 3-log reduction of the BCR-ABL transcript in comparison to the standardized baseline or a BCR-ABL (international scale) $0.1 \% .^{12}$ There is a good correlation between the BCR-ABL (international scale) levels in the peripheral blood and the bone marrow cytogenetical findings. A 1-log reduction or BCR$\mathrm{ABL}$ (international scale) $10 \%$ is equivalent to a major cytogenetic response and a 2-log reduction or a BCR-ABL (international scale) $1 \%$ is equivalent to a complete cytogenetic response. Elimination of the leukemic stem cell is the ultimate goal of treatment and the only potential for a CML cure.

Complete molecular response is defined as undetectable BCR-ABL mRNA transcripts by RQ-PCR and/or nested PCR in 2 consecutive high-quality samples (sensitivity $\left.>10^{4}\right) .{ }^{10}$ However, the ultimate goal of treatment, elimination of the leukemic stem cells and cure, can not be shown with all these methods.

If conventional cytogenetics of the bone marrow is performed, there is additional information about bone marrow morphology by bone marrow smears and about additional chromosomal changes. The molecular monitoring lacks this advantages..$^{13}$

ELN recommends performing molecular BCRABL RQ-PCR-analysis at diagnosis, every 3 months until MMR has been achieved and confirmed, then at least every 6 months. Regular molecular monitoring over the course of disease can help making treatment decisions for example in patients who are responding slowly to treatment or are not using the drug adherently. ${ }^{14} \mathrm{~A}$ rise in BCR-ABL transcript levels detected during TKI treatment is a warning sign and a confirmative RQ-PCR analysis should be performed. ${ }^{15}$

Achievement of major molecular response at 18 months is an optimal response to imatinib treatment. Several studies have demonstrated that achievement of a major molecular response is associated with prolonged durations of complete cytogenetic response in comparison to the patients who did not have the same depth of BCR-ABL levels..$^{16,17}$ The degree of molecular response at early time points may predict later achievement and sustain of major molecular response and improved rates of progression free and event free survival. ${ }^{18}$

Minor changes in BCR-ABL should not necessitate a treatment change. If there is an increase of 510 fold or greater, confirmation of the test and additional assessments such as cytogenetic analysis and mutation analysis should be done. ${ }^{7,19}$

The National Comprehensive Cancer Network $(\mathrm{NCCN})$ published evidence-based clinical practice guidelines for CML and proposed indications for cytogenetics and PCR for BCR-ABL quantification, and indications for bcr-abl domain mutation analysis..$^{15}$

\section{SAFETY PROFILES OF THE VARIOUS TKIS}

The safety profiles of the various TKIs differ from each other, because there are differences in the targeted tyrosine kinases of these compounds. In the pivotal phase III International Randomized Study of Interferon and STI571 (IRIS) trial over 8 years of follow-up 5.4\% of patients had discontinued treatment because of adverse events..$^{20}$ The most common grade $3 / 4$ hematologic adverse events among imatinib-treated patients in IRIS were neutropenia, thrombocytopenia, and anemia. ${ }^{21}$ Adverse events 
occurred mostly in the first two years and decreased to less than $2 \%$ after 4 years of imatinib therapy.22 Imatinib had a favorable long term safety profile after 5 year results of IRIS..$^{23}$

There has not been a trial comparing second-generation TKIs to one another, but there have been studies for each where they have been compared with imatinib. Nilotinib was rationally designed based on the structure of imatinib, but its safety profile is very different from that of imatinib. Nilotinib does not cause fluid retention as frequently as imatinib, but is associated with higher rates of asymptomatic pancreatic lipase elevation. ${ }^{24,25}$ Dasatinib produces more myelosuppression compared to imatinib. Bleeding and pleural effusions are the non-desired effects of dasatinib. ${ }^{24}$ Grade I-II cytopenias and biochemical abnormalities usually recover after withholding the drug. Dasatinib $100 \mathrm{mg}$ once daily instead of $70 \mathrm{mg}$ twice daily minimized the occurrence of pleural effusions. ${ }^{26}$ If the pleural effusion does not resolve with interruption of dasatinib treatment, diuretics and corticosteroids can be added to the treatment. If the pleural effusion reoccurs, dose reduction is needed. ${ }^{26}$

\section{LONG TERM EFFECTS OF TKIs}

Discontinuation of TKIs in CML patients is associated with a high risk of relapse. Therefore tyrosine kinase inhibitors should be given during the lifespan of the patient. TKIs impact multiple targets for long period of time, which can induce late side effects. The extent and nature of potential late effects are important for physicians to consider. These effects could be either harmful, or beneficial.

\section{Cardiac Effects of TKIs}

All of the clinically available TKI inhibitors contain the information of the potential for cardiotoxicity in their respective package inserts. Severe congestive heart failure and left ventricular dysfunction have been reported rarely with especially high dose imatinib treatment. The general consensus is that the majority of patients who develop cardiotoxicity, heart failure, and/or myocardial infarction are older (>65 years old) and have pre-existing cardiac risk factors or existing cardiac disease. ${ }^{27,28}$ Cardiac failure is also very uncommon in CML patients on nilo- tinib and dasatinib therapy. Prolongation of the QTc interval is relatively uncommon with both nilotinib $^{29}$ and dasatinib. ${ }^{30}$ FDA maintains a warning for nilotinib regarding QTc prolongation. If the QTc is $>480 \mathrm{msec}$, therapy should be withheld and serum potassium and magnesium levels corrected, if below normal. Concomitant medication that can prolong QTc should also be checked. Treatment should be resumed at the previous dose in $<2$ weeks if the QTc returns to $<450 \mathrm{msec}$ and $<20 \mathrm{msec}$ of baseline. Neither nilotinib nor dasatinib should be administered to patients with long QT syndrome and with drugs known to prolong QTc. ${ }^{15}$

\section{Immune System}

In addition to BCR-ABL, TKIs inhibit other proteins, some of which play a role in the immune system. Imatinib therapy induces hypogammaglobulinemia $^{31}$ and impairs the T-cell response ${ }^{32}$ directly. Indirectly, inhibition of the dendritic cell function can also affect T-cell function. ${ }^{33}$ Thus, imatinib use can help to improve graft versus host disease $(G V H D) .{ }^{34}$ Nilotinib reduces proliferation and function of CD 8+ T-lymphocytes..$^{35}$ Dasatinib seems to be a more potent immuno-modulating agent. Dasatinib suppresses T-cell function and causes an expansion of the natural killer cell compartment, while suppressing NK cytotoxicity ${ }^{36,37}$ Large, granular lymphocytosis ${ }^{38}$ is observed in patients on dasatinib treatment. This fact might be associated with improved response in CML.

\section{Bone}

The phosphate metabolism can be affected by the use of TKIs and decreased serum phosphate levels are seen occasionally in patients with CML using TKIs. ${ }^{39}$ Furthermore, inhibition of PDGFR signalling by imatinib in osteoblasts activates osteoblast differentiation and inhibits proliferation. ${ }^{40}$ Imatinib inhibits osteoclastogenesis by both stromal cell-dependent and direct effects on osteoclast precursors. ${ }^{41}$ Taking together, the effects of imatinib on bone metabolism potentially have useful clinical effects, where the bone mass is protected and preserved. 


\section{Gynecomastia}

KIT and PDGFR are expressed in the male testis. Imatinib can decrease testosterone production by the inhibition of these receptors. ${ }^{42}$ Long-term imatinib exposure can cause secondary inhibition of KIT and PDGFR, which can decrease testosterone production over time. In one study hormone levels and clinical evidence of gynecomastia were evaluated in 38 patients at baseline and on treatment with imatinib..$^{42}$ In the majority of patients studied, imatinib was associated with a decrease in the production of testicular hormones, and in 7 patients gynecomastia was noted.

\section{Hypothyroidism}

Imatinib has no direct effect on hypothyroidism in patients with CML. But it can affect patients treated with levothyroxine for hypothyroidism. In a cohort of 11 patients (10 with medullary thyroid carcinoma and 1 with GIST) treated with imatinib and levothyroxine concurrently. ${ }^{43}$ Symptomatic hypothyroidism occurred in all patients, in which thyroid gland was removed surgically. Hypothyroidism was not present in those who did not undergo surgery. Patients with surgery had markedly elevated thyroid-stimulating hormone (TSH) levels and required an increase of levothyroxine during imatinib treatment. ${ }^{43}$ At present it can be suggested to monitor TSH levels more frequently in imatinib-treated patients on thyroid hormone replacement.

\section{Long Term Cutaneous Toxicity}

Rush, dry skin, pruritus, and photosensitivity are early dermatologic adverse events but may persist throughout therapy. ${ }^{44}$ Other form of cutaneous toxicity associated with imatinib is skin hyper/hypo pigmentation, which can persist even after imatinib is stopped. ${ }^{45}$ Hypopigmentation is related to the inhibition of KIT and is more prevalent in ethnically pigmented patients. In a group of 133 patients repigmentation of gray hair has been reported. ${ }^{46}$

\section{Secondary Malignancies}

During the course of CML treated with imatinib alone or in combination with other agents occasionally other chromosomal abnormalities in the $\mathrm{Ph}$ - negative metaphases can arise. This may be the initiator of development of myelodysplastic syndrome/acute myelogenous leukemia (MDS/AML). In a study comprising 1701 patients 3 patients treated with imatinib for CML developed AML $(n=1)$ and high-risk MDS $(n=2) .{ }^{47}$ In a further series of patients with newly diagnosed CML treated with firstline imatinib chromosomal abnormalities in Ph-negative metaphases occurred in $9 \%$ of patients. ${ }^{48} \mathrm{~A}$ patient with monosomy 7 developed AML, but the other patients had no signs of myelodysplasia or acute leukemia. These chromosomal changes can occur in patient with CML treated with alternative drugs, including interferon, nilotinib and dasatinib. ${ }^{49-52}$ Thus, it is useful to monitor patients on TKIs with bone marrow aspirations and cytogenetic analysis if a secondary clonal evolution is suspected.

\section{ADHERENCE TO TREATMENT}

Continuous and adequate imatinib dosing is essential to achieve therapeutic outcomes. ${ }^{53}$ The healthcare provider's recommendations should be agreed and kept by the patients in order to achieve better responses. This is reflected by the adherence of the patient to treatment. ${ }^{54}$ Although mainly it is a problem of the patient, adherence behavior is influenced also by the clinician and the healthcare system, the disease and its treatment, and economic and social factors. The ADAGIO (Adherence Assessment with Glivec: Indicators and Outcomes) study suggested that nonadherence is more prevalent than patients, physicians, and third persons such as spouses and family members believe it is, and is related to poorer response rates to imatinib..$^{55}$

Among the others, the dosing schedule of the drug is very important for the patients to adhere to treatment. One would expect that once daily dosing regimens would be more convenient for patients with CML, who are in good medical condition and go to work or perform their daily activities like normal people.

\section{Can we Stop TKIs?}

The stop imatinib (STIM) trial enrolled 100 patients who discontinued imatinib after achieving and maintaining CMR for 2 years or more. Sixty-nine 
patients were followed up at least 12 months (median 24 months), and in 42 (61\%) BCR-ABL transcripts re-emerged. In the remaining patients CMR sustained. All but one of these molecular recurrences occurred within 7 months of stopping imatinib, and all patients with recurrent disease responded again to imatinib treatment.

The authors estimate that $10 \%$ of patients with CML may be eligible for an attempt of imatinib discontinuation. ${ }^{56}$ With a $40 \%$ rate of sustained CMR, $4 \%$ of CML patients may be 'cured' with imatinib. However, this data are preliminary and observation time is too short. Occasional relapses have been reported almost two decades after allogeneic stem cell transplant. ${ }^{57}$ Thus, a longer follow-up time will be needed before making a definite decision.

\section{CONCLUSION}

In conclusion, TKIs have revolutionized the treatment of CML and changed the natural history of the disease. The efficacy and safety of imatinib, dasatinib and nilotinib have been confirmed by substantial long-term outcome and response durability data. To optimize therapeutic benefit, clinicians should monitor the patients using TKIs closely and be aware of long-term undesired effects of TKIs.

\section{REFERENCES}

1. Nowell PC, Hungerford DA. A minute chromosome in human granulocytic leukemia. Science 132: 1497, 1960.

2. Rowley JD. A new consistent chromosomal abnormality in chronic myelogenous leukemia identified by quinacrine fluorescence and Giemsa staining. Nature 243: 290-293, 1973.

3. de Klein A, van Kessel AG, Grosveld G, et al. A cellular oncogene is translocated to the Philadelphia chromosome in chronic myelocytic leukaemia. Nature 300: 765-767, 1982

4. Sawyers CL. Chronic myeloid leukemia. N Engl J Med 340: 1330-1340, 1999.

5. Schiffer CA. BCR-ABL tyrosine kinase inhibitors for chronic myelogenous leukemia. N Engl J Med 357: 258-265, 2007.

6. O'Brien SG, Guilhot F, Larson RA, et al. Imatinib compared with interferon and low-dose cytarabine for newly diagnosed chronic-phase chronic myeloid leukemia. N Engl J Med 348: 994-1004, 2003.
7. Baccarani M, Saglio G, Goldman J, et al. Evolving concepts in the management of chronic myeloid leukemia: recommendations from an expert panel on behalf of the European LeukemiaNet. Blood 108: 1809-1820, 2006.

8. Baccarani M, Cortes J, Pane F, et al. Chronic myeloid leukemia: an update of concepts and management recommendations of European LeukemiaNet. J Clin Oncol 27: 6041-6051, 2009.

9. Kantarjian HM, O'Brien S, Cortes JE, et al. Complete cytogenetic and molecular responses to interferonalpha-based therapy for chronic myelogenous leukemia are associated with excellent long-term prognosis. Cancer 97:1033-1041, 2003.

10. Kantarjian $\mathrm{H}, \mathrm{O}$ 'Brien $\mathrm{S}$, Shan J, et al. Cytogenetic and molecular responses and outcome in chronic myelogenous leukemia: need for new response definitions? Cancer 112: 837-845, 2008.

11. Cross NC, Feng L, Chase A, et al. Competitive polymerase chain reaction to estimate the number of BCR$A B L$ transcripts in chronic myeloid leukemia patients after bone marrow transplantation. Blood 82: 19291936, 1993.

12. Hughes TP, Kaeda J, Branford S, et al. Frequency of major molecular responses to imatinib or interferon alfa plus cytarabine in newly diagnosed chronic myeloid leukemia. N Engl J Med 349: 1423-1432, 2003.

13. Guilhot F, Larson RA, O'Brien SG, et al. Time to complete cytogenetic response (CCyR) does not affect long-term outcomes for patients on imatinib therapy [abstract]. Blood 110: 16, 2007.

14. Hughes T, Deininger M, Hochhaus A, et al. Monitoring CML patients responding to treatment with tyrosine kinase inhibitors: review and recommendations for harmonizing current methodology for detecting BCR$A B L$ transcripts and kinase domain mutations and for expressing results. Blood 108: 28-37, 2006.

15. The NCCN Chronic myelogenous leukemia clinical practice guidelines in oncology (Version 2.2011). (C) 2010 National Comprehensive Cancer Network, Inc. http://www.nccn.org (Access date: November 2, 2010).

16. Cortes J, Talpaz M, O'Brien S, et al. Molecular responses in patients with chronic myelogenous leukemia in chronic phase treated with imatinib mesylate. Clin Cancer Res 11: 3425-3432, 2005.

17. lacobucci I, Saglio G, Rosti G, et al. Achieving a major molecular response at the time of a complete cytogenetic response (CCgR) predicts a better duration of CCgR in imatinib-treated chronic myeloid leukemia patients. Clin Cancer Res 12: 3037-3042, 2006.

18. Quintas-Cardama A, Kantarjian H, Jones $D$, et al. Delayed achievement of cytogenetic and molecular response is associated with increased risk of progression among patients with chronic myeloid leukemia in early chronic phase receiving high-dose or standarddose imatinib therapy. Blood 113: 6315-6321, 2009. 
19. Hughes T, Deininger M, Hochhaus A, et al. Monitoring $\mathrm{CML}$ patients responding to treatment with tyrosine kinase inhibitors: Review and recommendations for harmonizing current methodology for detecting BCR$\mathrm{ABL}$ transcripts and kinase domain mutations and for expressing results. Blood 108: 28-37, 2006.

20. Deininger M, O'Brien SG, Guilhot F, et al. International randomized study of interferon vs STI571 (IRIS) 8-year follow up: sustained survival and low risk for progression or events in patients with newly diagnosed chronic myeloid leukemia in chronic phase (CML-CP) treated with imatinib. 51st ASH Annual Meeting, December 58 New Orleans. Blood 114: 462, 2009.

21. O'Brien SG, Guilhot F, Larson RA, et al. Imatinib compared with interferon and low-dose cytarabine for newly diagnosed chronic-phase chronic myeloid leukemia. N Engl J Med 348: 994-1004, 2003.

22. Druker BJ, Guilhot F, O'Brien SG, et al. Five-year follow-up of patients receiving imatinib for chronic myeloid leukemia. N Engl J Med 355: 2408-2417, 2006.

23. Hochhaus A, O'Brien SG, Guilhot F, et al. Six-year followup of patients receiving imatinib for the first-line treatment of chronic myeloid leukemia. Leukemia 23: 1054-1061, 2009.

24. Carpiuc KT, Stephens JM, Liou SY, Botteman MF. Incidence of grade 3/4 adverse events in imatinib resistant/ intolerant chronic phase CML (CP-CML): a comparison of nilotinib and dasatinib. J Clin Oncol 25: 680, 2007.

25. Cortes JE, Jones D, O'Brien S, et al. Nilotinib as frontline treatment for patients with chronic myeloid leukemia in early chronic phase. J Clin Oncol 28: 392397, 2010.

26. Shah NP, Kantarjian HM, Kim DW, et al. Intermittent target inhibition with dasatinib $100 \mathrm{mg}$ once daily preserves efficacy and improves tolerability in imatinibresistant and -intolerant chronic-phase chronic myeloid leukemia. J Clin Oncol 26: 3204-3212, 2008.

27. Atallah E, Durand JB, Kantarjian H, Cortes J. Congestive heart failure is a rare event in patients receiving imatinib therapy. Blood 110: 1233-1237, 2007.

28. Ribeiro AL, Marcolino MS, Bittencourt HN, et al. An evaluation of the cardiotoxicity of imatinib mesylate. Leuk Res 32: 1809-1814, 2008.

29. Tasigna (nilotinib). Nilotinib prescribing information. East Hanover: Novartis Pharmaceuticals Corporation; 2007. Revised October.

30. Sprycel (dasatinib). Dasatinib prescribing information. New York, NY: Bristol-Myers Squibb; 2007. Revised November.

31. Steegmann JL, Moreno G, Alaez C, et al. Chronic myeloid leukemia patients resistant to or intolerant of interferon alpha and subsequently treated with imatinib show reduced immunoglobulin levels and hypogammaglobulinemia. Haematologica 88: 762-768, 2003.

32. Cwynarski K, Laylor R, Macchiarulo E, et al. Imatinib inhibits the activation and proliferation of normal $T$ lymphocytes in vitro. Leukemia 18: 1332-1339, 2004.
33. Mohty M, Jourdan E, Mami NB, et al. Imatinib and plasmacytoid dendritic cell function in patients with chronic myeloid leukemia. Blood 103: 4666-4668, 2004.

34. Olivieri A, Locatelli F, Zecca M, et al. Imatinib for refractory chronic graft-versus-host disease with fibrotic features. Blood 114: 709-718, 2009.

35. Chen J, Schmitt A, Chen B, et al. Nilotinib hampers the proliferation and function of CD8+ $\mathrm{T}$ lymphocytes through inhibition of $\mathrm{T}$ cell receptor signalling. $J$ Cell Mol Med 12: 2107-2118, 2008.

36. Blake S, Hughes TP, Mayrhofer G, Lyons AB. The Src/ABL kinase inhibitor dasatinib (BMS-354825) inhibits function of normal human T-lymphocytes in vitro. Clin Immunol 127: 330-339, 2008.

37. Weichsel R, Dix C, Wooldridge L, et al. Profound inhibition of antigen-specific T-cell effector functions by dasatinib. Clin Cancer Res 14: 2484-2491, 2008.

38. Mustjoki S, Ekblom M, Arstila TP, et al. Clonal expansion of T/NK-cells during tyrosine kinase inhibitor dasatinib therapy. Blood 116: 772-782, 2010

39. Osorio S, Noblejas AG, Durán A, Steegmann JL. Imatinib mesylate induces hypophosphatemia in patients with chronic myeloid leukemia in late chronic phase, and this effect is associated with response. Am J Hematol 82: 394-395, 2007.

40. Berman E, Nicolaides M, Maki RG, et al. Altered bone and mineral metabolism in patients receiving imatinib mesylate. N Engl J Med 354: 2006-2013, 2006.

41. Vandyke K, Fitter S, Dewar AL, et al. Dysregulation of bone remodeling by imatinib mesylate. Blood 115: 766-774, 2010.

42. Gambacorti-Passerini C, Tornaghi L, Cavagnini F, et al. Gynaecomastia in men with chronic myeloid leukaemia after imatinib. Lancet. 361: 1954-1956, 2003.

43. de Groot JW, Zonnenberg BA, Plukker JT, et al. Imatinib induces hypothyroidism in patients receiving levothyroxine. Clin Pharmacol Ther 78: 433-438, 2005.

44. Valeyrie L, Bastuji-Garin S, Revuz J, et al. Adverse cutaneous reactions to imatinib (STI571) in Philadelphia chromosome-positive leukemias: a prospective study of 54 patients. J Am Acad Dermatol 48: 201206, 2003.

45. Arora B, Kumar L, Sharma A, et al. Pigmentary changes in chronic myeloid leukemia patients treated with imatinib mesylate. Ann Oncol 15:358-359, 2004.

46. Etienne G, Cony-Makhoul P, Mahon FX. Imatinib mesylate and gray hair. N Engl J Med 347: 446-447, 2002.

47. Kovitz C, Kantarjian H, Garcia-Manero G, et al. Myelodysplastic syndromes and acute leukemia developing after imatinib mesylate therapy for chronic myeloid leukemia. Blood 108: 2811-2813, 2006. 
48. Jabbour E, Kantarjian HM, Abruzzo LV, et al. Chromosomal abnormalities in Philadelphia chromosome negative metaphases appearing during imatinib mesylate therapy in patients with newly diagnosed chronic myeloid leukemia in chronic phase. Blood 110: 2991 2995, 2007.

49. Terre C, Eclache V, Rousselot P, et al. Report of 34 patients with clonal chromosomal abnormalities in Philadelphia-negative cells during imatinib treatment of Philadelphia-positive chronic myeloid leukemia. Leukemia 18: 1340-1346, 2004.

50. Fabarius A, Haferlach C, Müler MC, et al. Dynamics of cytogenetic abberations in Phildelphia chromosome positive and negative hematopoiesis during dasatinib therapy of chronic myeloid leukemia patients after imatinib failure. Haematologica 92: 834-837, 2007.

51. De Melo VAS, Milojkovic D, Khorashad JS, et al. Philadelphia-negative clonal hematopoiesis is a significant feature of dasatinib therapy for chronic myeloid leukemia. Blood 110: 3086-3087, 2007.

52. Jabbour E, Kantarjian H, Abruzzo L, et al. Chromosomal abnormalities in Philadelphia Chromosome (Ph)negative metaphases appearing during novel tyrosine kinase inhibitors (NTKI) therapy in patients (pts) with chronic myeloid leukemia (CML) after imatinib-failure. 48th ASH Annual Meeting, December 9-12, Orlando. Blood 108: 2115, 2006.

53. Stone RM. Optimizing treatment of chronic myeloid leukemia: a rational approach. Oncologist 9: 259-270, 2004.

54. Sabate E. Adherence to long-term therapies: evidence for action. Geneva, World Health Organization. 2003.

55. Noens L, van Lierde MA, De Bock R, et al. Prevalence, determinants, and outcomes of nonadherence to imatinib therapy in patients with chronic myeloid leukemia: the ADAGIO study. Blood 113: 5401-5411, 2009.
56. Mahon FX, Rea D, Guilhot J, et al. Discontinuation of imatinib in patients with chronic myeloid leukaemia who have maintained complete molecular remission for at least 2 years: the prospective, multicentre stop imatinib (sTiM) trial. Lancet Oncol 11: 1029-1035, 2010.

57. Goldman JM, Majhail NS, Klein JP, et al. Relapse and late mortality in 5-year survivors of myeloablative allogeneic hematopoietic cell transplantation for chronic myeloid leukemia in first chronic phase. J Clin Oncol 28: 1888-1895, 2010.

\section{Correspondence}

Dr. Akif Selim YAVUZ

İstanbul Üniversitesi İstanbul Tıp Fakültesi

İç Hastalıkları Anabilim Dalı, Hematoloji Bilim Dalı 34390 Çapa, İstanbul / TURKEY

Tel: (+90.212) $4142000 / 33183$

Fax: (+90.212) 5231888

e-mail: yavuzas@istanbul.edu.tr 